\title{
Growth and Flowering of Petunia and Impatiens: Effects of Competition and Reduced Water Content Within a Container
}

\author{
Tijana Blanusa ${ }^{1}$ \\ Royal Horticultural Society, Wisley, Surrey, GU23 6QB, U.K.; and School of \\ Biological Sciences, University of Reading, Whiteknights, Reading RG6 6AS, \\ U.K.
}

\section{Eleni Vysini and Ross W.F. Cameron School of Biological Sciences, University of Reading, Whiteknights, Reading RG6 6AS, U.K.}

Additional index words. bedding plants, water use efficiency, efficiency of flowering, bud abortion, regulated deficit irrigation

\begin{abstract}
The primary objective of this research was to determine how the presence of more than one plant and more than one species in a container influence plant quality, particularly when the volume of water given to the container is reduced. Petunia $\times$ hybrida 'Hurrah White' and Impatiens 'Cajun Violet' were chosen as typical bedding plant species. Plants were grown in 2 I containers either under " $100 \%$ ETp" (i.e., replacing all the water lost by evapotranspiration in the previous $24 \mathrm{~h}$ ) or under a moisture-restrictive regime of " $25 \%$ ETp," in which plants received $25 \%$ of the " $100 \%$ ETp" value. An ancillary experiment investigated whether low watering resulted in floral buds being aborted. Results demonstrated that watering requirements of Petunia under " $100 \%$ ETp" (i.e., replacing all the water lost by evapotranspiration in the previous $24 \mathrm{~h}$ ) were on average $30 \%$ greater than those of Impatiens. However, when two Petunia plants were growing in the same container, the volume of water required to maintain soil moisture content at container capacity was on average only $10 \%$ greater than for a single plant. Under a " $25 \%$ ETp" regime in which plants received $25 \%$ of the " $100 \%$ ETp" value, flower number, plant height, and flower size were reduced by $50 \%, 33 \%$, and $13 \%$, respectively, in Petunia compared with " $100 \%$ ETp." For example, flower numbers decreased from an average of 71 to 33 flowers per plant in " $100 \%$ ETp" and " $25 \%$ ETp," respectively. Petunia plants in the " $25 \%$ ETp" regime, however, were more efficient at producing both biomass and flowers in relation to the volume of water applied. Petunia plants that experienced both competition from other plants in the container and lower irrigation rates had enhanced efficiency of flower production (i.e., more flowers per unit biomass). For Impatiens, however, the growing of single plants at " $25 \%$ ETp" was plausible, but the addition of a Petunia plant at " $25 \%$ ETp" was detrimental to plant quality (Impatiens flower numbers reduced by $75 \%$ ).
\end{abstract}

Bedding plants are a popular feature in the urban landscape, being widely used in public parks, town centers, and private gardens (as planted plants but also in containers and hanging baskets). Despite many annual bedding plants being derived from species adapted to semidesert or Mediterranean climates (Philips and Rix, 2002), many modern cultivars are identified as water-demanding (Henson et al., 2006; Niu et al., 2006). In light of changing climatic patterns and a greater demand for water for domestic and industrial use (Arnell, 1998), there is pressure on local authorities to minimize irrigation

Received for publication 19 Mar. 2009. Accepted for publication 8 May 2009

Provision of seeds by S\&G seeds is gratefully acknowledged.

${ }^{1}$ To whom reprint requests should be addressed; e-mail tijanablanusa@rhs.org.uk. applied to ornamental plants. As a consequence, bedding plants are being replaced in many landscapes by more xerophytic but often less colorful species, many of which rely on foliage rather than flowers for their display (Franco et al., 2006). In addition to affecting the market for bedding plants, these alternative species are often less popular with the public. In the private garden too, there is pressure to reduce watering, particularly during warm periods in summer; e.g., in the United Kingdom, garden watering can account for $70 \%$ of domestic water use at peak times (Hunt, 2006). When water savings are not achieved, hosepipe bans restricting the use of water in the garden are introduced (Sims, 2006). Therefore, maintaining the ornamental properties of bedding plants with minimal water input would enable them to survive, literally and figuratively, in the urban landscape (Henson et al., 2006).
Commercial growers often subject ornamental plants to water deficits to restrict the growth and produce a compact plant to the specification of the retailer (Cameron et al., 1999; Clark et al., 2004; Franco et al., 2006; van Iersel and Nemali, 2004). Compactness may be an advantage during the production and retail stages, because plants become more manageable requiring less space, less frequent pruning, and reduced irrigation (Cameron et al., 2006). Studies of bedding plants have concentrated on the physiological responses of ornamental plants to water deficits during plant production (Nemali and van Iersel, 2008; Niu et al., 2006) with implications for retail quality (Armitage and Kowalski, 1983 ) or ability to establish in the landscape (Armitage and Kowalski, 1983; Henson et al., 2006; Scheiber and Beeson, 2006). In contrast, few studies have focused in detail on how water availability affects flowering performance after planting and over longer term. Information from other ornamental plant groups suggests that flower numbers are reduced during water deficits (Niu et al., 2007). In Rhododendron, severe, but not moderate, water deficits reduced flower numbers and also produced more compact plants (Cameron et al., 1999). Mechanisms causing a decrease in floral numbers may differ between species and can include disturbed floral initiation (Cawoy et al., 2006), floral abortion (Turner, 1993), or simply a decrease in plant size resulting in fewer locations for flower initiation (Guilioni et al., 2003).

Furthermore, bedding plants are seldom grown as single plants in containers. In practice, several plants and several species constitute a mixed container or a hanging basket, in which individual species are likely to differ in vigor (Ray et al., 2003) and to have different watering requirements. Interactions between multiple plants and species and their impact on resource allocation to roots and shoots have been studied in some detail in ecological studies, e.g., legumes (Callaway, 2002; Murphy and Dudley, 2007), and in weed-crop interactions (FroudWilliams, 2002), but little attention has focused on competitive effects that may occur in the constrained environment of a container. Similarly, it is not documented how rationalizing the amount of water applied to a container affects the ornamental properties of an individual plant when grown alongside either others of the same species or those of an alternative species.

In our study, Petunia $\times$ hybrida 'Hurrah White' and Impatiens 'Cajun Violet' were chosen as typical bedding subjects and two watering regimes were applied to examine how water availability influenced subsequent development. Primary interest was with Petunia because it is the more droughtresistant of the two (Henson et al., 2006) and hence a better candidate for future planting schemes. Objectives in the first experiment were to determine how the presence of more than one plant and more than one species in a container influence plant quality, particularly when the volume of 
water given to the container is reduced. A second experiment was implemented to investigate whether low watering regimes resulted in floral buds being aborted.

\section{Materials and Methods}

Plant material and planting combinations. Plants of Petunia $\times$ hybrida 'Hurrah White' (Expts. 1 and 2) and Impatiens 'Cajun Violet' (Expt. 1) were grown from seed (S\&G, Halsall, U.K.) in 3-cm cellular trays in a peatbased medium (SHL seed compost; William Sinclair, Lincoln, U.K.) for 6 weeks within a glasshouse. At this point, the plants were transplanted into 2-L containers with peatbased medium (SHL universal potting compost; William Sinclair).

Between transplanting and the start of the experiment $(3 \mathrm{~d})$, moisture in all containers was maintained at container capacity. After transplanting, plants were moved to an unshaded glasshouse and randomly distributed. The glasshouse was ventilated only when temperature rose above $21^{\circ} \mathrm{C}$ to minimize the chance of rain entering the compartment while the vents were open. Minimum (nighttime) and maximum (daytime) air temperatures in glasshouse compartments were recorded daily.

In Expt. 1, plant combinations per 2-L container were: P, single Petunia specimen; I, single Impatiens; PP, two Petunia, and PI, single Petunia together with single Impatiens. In Expt. 2, single Petunia plants were grown.

Regulated deficit irrigation. Plants were grown for $30 \mathrm{~d}$ under the "100\% ETp" (potential evapotranspiration) regime (i.e., replacing all the water lost by evapotranspiration in the previous $24 \mathrm{~h}$ ) or under " $25 \%$ ETp." There were seven and eight replicates of each planting combination in Expts. 1 and 2, respectively, at each ETp level.

Daily ETp from the crop was determined by monitoring weight loss from the containers over $24 \mathrm{~h}$. Three containers per plant combination in a " $100 \%$ ETp" treatment were weighed daily at $1500 \mathrm{HR}$ and were watered back to container capacity by hand. The remaining containers in the " $100 \%$ ETp" treatment were then watered based on the average value for weighed containers, ensuring water was evenly applied across the medium surface to avoid any bias in distribution. Additionally, saucers were placed under the containers to enable reabsorption of any leachate. Plants in the " $25 \%$ ETp" treatment in most cases received $25 \%$ of the " $100 \%$ ETp" value; however, after Day 15, irrigation volume was occasionally increased here to enable substrate moisture content (SMC) to be maintained between 0.10 and $0.15 \mathrm{~m}^{3} \cdot \mathrm{m}^{-3}$. This is because our preliminary experiments showed that decreasing SMC below $0.10 \mathrm{~m}^{3} \cdot \mathrm{m}^{-3}$ correlated with permanent wilting and loss of ornamental qualities.

Measurement of substrate moisture content, leaf stomatal conductance, and plants' growth responses. Substrate moisture content in both experiments was measured twice weekly between 0900 and 1000 HR using a SM200
Soil Moisture Probe (Delta-T Devices Ltd., Cambridge, U.K.). Two measurements, $\approx 5$ $\mathrm{cm}$ either side of the plant stem, were made per container and the average value used for analyses.

In Expt. 1, plant height, number of shoots present, and numbers of buds (Petunia only) or open flowers were recorded on each plant at the start and then as the SMC in the " $25 \%$ ETp" treatment reached $\approx 25 \%$ of the " $100 \%$ ETp" treatment (Day 12) and again 2 weeks into the induced SMC (Day 29). Flower diameter (Petunia only) was measured on five flowers per plant and values were averaged. We also calculated water use efficiency (i.e., shoot biomass and flower production in relation to the amount of water applied) and efficiency of flower production (i.e., flower number/g dry shoot weight). Water use efficiency was calculated by dividing shoot dry weight or flower number of individual plants by either the total amount of water applied to the whole container or the estimated amount of water that was available to each plant. In case of a container with a single plant, these volumes were equal; in cases of containers with two plants, however, the watering amount per plant was estimated as half that applied to a whole container.

In Expt. 2, plant height, shoot number, bud and flower numbers were measured approximately every 3 to $4 \mathrm{~d}$. Dry shoot weight was measured at the end. On Days 8 , 11,15 , and 18 , emerging floral buds (greater than $5 \mathrm{~mm}$ ) were tagged, and the rate of their conversion into flowers was monitored twice weekly by counting the numbers of open flowers. Plants' water relations (Expt. 2 only) were monitored through leaf stomatal conductance $\left(g_{s}\right)$ measured between 1000 and 1200 HR using a AP-4 Leaf Porometer (Delta-T Devices Ltd., Cambridge, U.K.); $g_{s}$ was measured on all plants (three leaves per plant) twice weekly (immediately after
SMC measurements) for the duration of the experiment.

Expts. 1 and 2 started on 27 Apr. and 4 Aug., respectively. During the experiments, data for sunshine duration and net radiation were collected from the weather station in close proximity of the glasshouse.

Statistical analysis. Data were analyzed using GenStat (Release 8.1; Lawes Agricultural Trust, Rothamsted Experimental Station, U.K.). Analysis of variance (ANOVA) was used to assess the effect of different watering regimes and the presence of a second plant on measured parameters; values were presented as means with associated least significant differences (LSD, $P=0.05$ ) and df. In Expt. 1, for the treatment in which two Petunias were grown in the same container, data for two plants were averaged before being entered into ANOVA. Data for Petunia and Impatiens were analyzed separately. In Expt. 2, to compare the percentages of flower buds developing into flowers, data for each date were analyzed using Fisher's exact test. The choice of test was dictated by a sample size and large number of $100 \%$ observations, which precluded the transformation of the data and ANOVA.

\section{Results}

\section{Expt. 1}

Total watering volumes in the " $25 \%$ ETp" treatment were on average $\approx 33 \%$ (rather than 25\%) of that applied to the plants in " $100 \%$ ETp" treatment (Fig. 1); this is the result of the intermittent addition of water to prevent the decrease in SMC to below 0.10 $\mathrm{m}^{3} \cdot \mathrm{m}^{-3}$. Under the " $100 \%$ ETp" regime, single Impatiens required on average $\approx 30 \%$ less water than single Petunia. Furthermore, two Petunia plants required only $\approx 10 \%$ more water than a single Petunia, but this difference was statistically significant (Fig. 1).

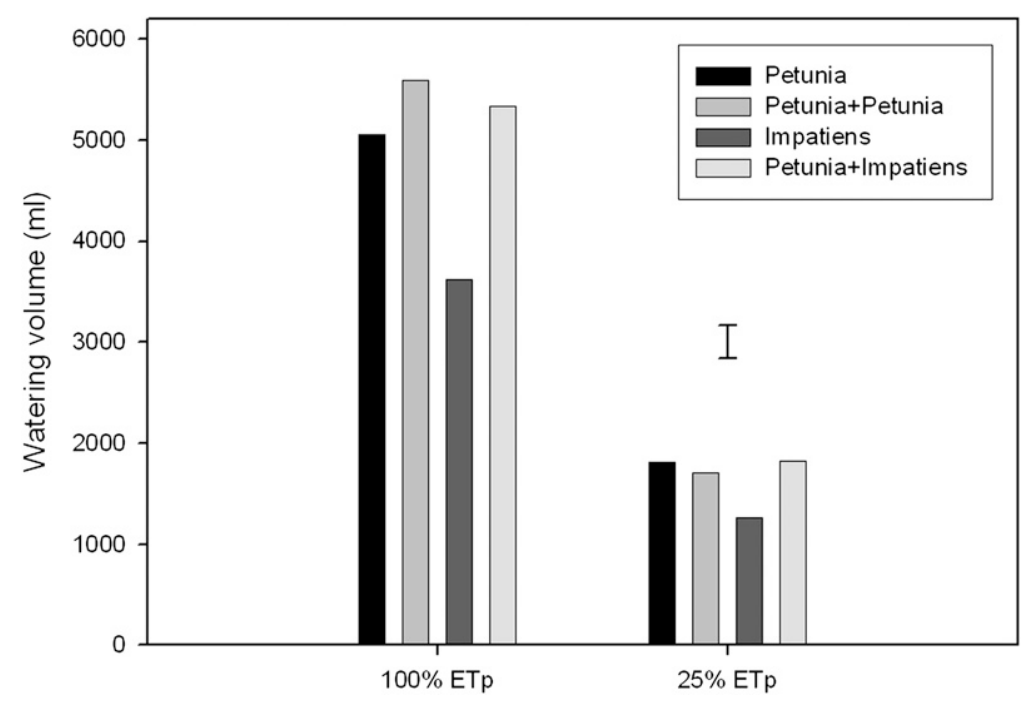

Fig. 1. Total mean volume of water applied to containers $(n=3)$ in each treatment during Expt. 1. Vertical line represents least significant difference $(\mathrm{df}=23)$. 
Substrate moisture content of the " $100 \%$ ETp" and " $25 \%$ ETp" treatments was different from Day 5 of the experiment $(P<$ 0.001; Fig. 2). From Day 12 until the end of the experiment, the SMC in " $25 \%$ ETp" plants was between 0.08 and $0.14 \mathrm{~m}^{3} \cdot \mathrm{m}^{-3}$; for plants in " $100 \%$ ETp" treatment, SMC was largely maintained between 0.3 and 0.4 $\mathrm{m}^{3} \cdot \mathrm{m}^{-3}$ (Fig. 2). Maximum (daytime) air temperatures during the course of the experiment averaged $39^{\circ} \mathrm{C}$; mean daily sunshine duration was $5.8 \mathrm{~h}$ (data not shown).

Ornamental properties-Petunia. Irrigation treatments were beginning to influence growth parameters by Day 12 with a significant reduction in the number of shoots pro- duced in the " $25 \%$ ETp" treatment (data not shown). By Day 29 (end of the experiment), plants in the " $25 \%$ ETp" treatment had a significantly reduced height, shoot number, dry weight, bud and flower number, and flower diameter (Table 1). However, in terms of water use efficiency (i.e., the shoot weight or flower number per volume of water applied), plants in the " $25 \%$ ETp" treatment were significantly more efficient than plants within the " $100 \%$ ETp" treatment (Table 2).

The number of plants and their combination in the container strongly influenced individual plants' performance. Placing two Petunia specimens in one container reduced plant height and shoot number per plant

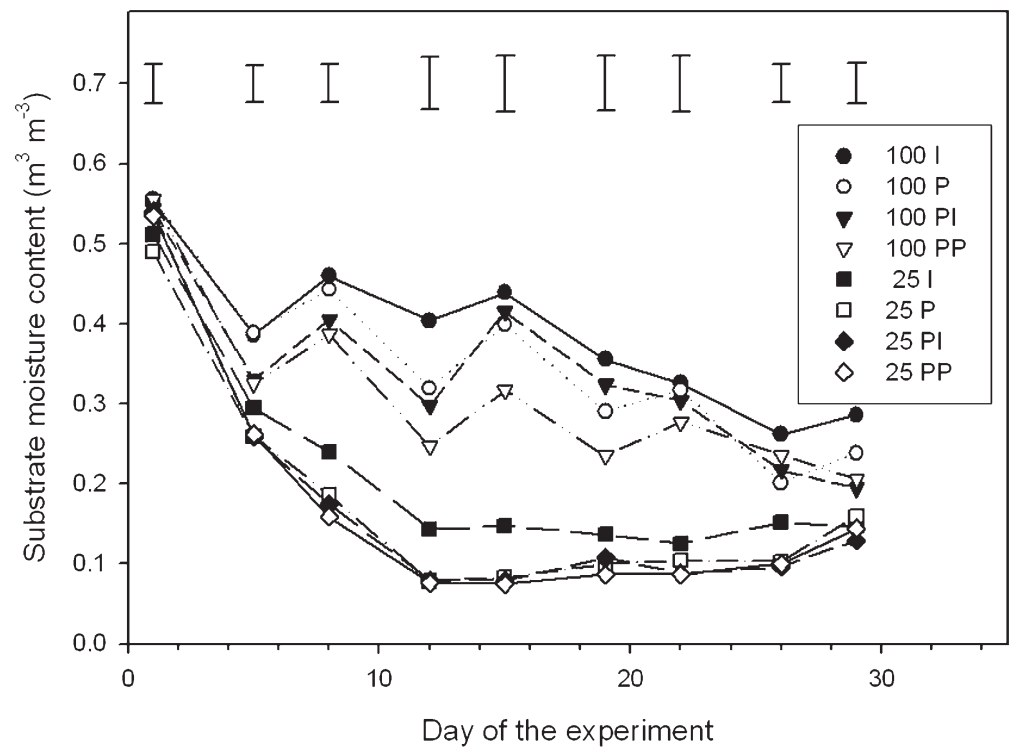

Fig. 2. Mean substrate moisture content per treatment/plant combination over the course of Expt. 1 . Vertical lines represent least significant difference $(\mathrm{df}=55)$. Plants were exposed to two different watering regimes (" $100 \%$ " or " $25 \%$ ETp") and combinations in the container ( $\mathrm{P}=$ one Petunia; $\mathrm{PP}=$ two Petunia; PI = Petunia + Impatiens, and I = one Impatiens).

Table 1. Mean plant height, shoot number, shoot dry weight, flower and bud number (per plant), and flower diameter of Petunia and Impatiens. ${ }^{\mathrm{z}}$

\begin{tabular}{|c|c|c|c|c|c|c|}
\hline & $\mathrm{Ht}(\mathrm{cm})$ & $\begin{array}{c}\text { Shoot } \\
\text { number }\end{array}$ & Dry wt (g) & $\begin{array}{l}\text { Flower } \\
\text { number }\end{array}$ & Bud number & $\begin{array}{c}\text { Flower } \\
\text { diam }(\mathrm{cm})\end{array}$ \\
\hline \multicolumn{7}{|l|}{ Petunia } \\
\hline 100P & 30.3 & 12.9 & 14.9 & 71.4 & 44.0 & 6.1 \\
\hline 100PP & 27.9 & 9.6 & 8.0 & 37.5 & 23.0 & 5.7 \\
\hline 100PI & 30.4 & 10.4 & 10.5 & 50.3 & 28.9 & 5.8 \\
\hline $25 \mathrm{P}$ & 21.1 & 9.7 & 6.6 & 32.6 & 32.6 & 5.5 \\
\hline $25 \mathrm{PP}$ & 20.3 & 6.4 & 3.2 & 17.3 & 16.6 & 5.3 \\
\hline 25PI & 21.4 & 7.4 & 5.0 & 26.9 & 21.6 & 5.4 \\
\hline $\begin{array}{l}\text { LSD } \\
\mathrm{df}=36\end{array}$ & 1.94 & 1.37 & 0.99 & 5.70 & 4.73 & 0.31 \\
\hline \multicolumn{7}{|l|}{ Impatiens } \\
\hline $100 \mathrm{I}$ & 19.9 & 8.3 & 7.5 & 35.7 & NA & NA \\
\hline 100PI & 22.0 & 5.9 & 3.9 & 26.7 & NA & NA \\
\hline $25 \mathrm{I}$ & 15.3 & 5.0 & 2.6 & 19.4 & NA & NA \\
\hline $25 \mathrm{PI}$ & 14.6 & 4.1 & 1.3 & 8.4 & NA & NA \\
\hline $\begin{array}{l}\text { LSD } \\
\mathrm{df}=24\end{array}$ & 2.75 & 1.26 & 0.83 & 9.26 & NA & NA \\
\hline
\end{tabular}

"Plants were exposed to different watering regimes ("100\%" or " $25 \%$ ETp") and combinations of plants in the container $(\mathrm{P}=$ one Petunia $; \mathrm{PP}=$ two Petunia $; \mathrm{PI}=$ Petunia + Impatiens, and $\mathrm{I}=$ one Impatiens $)$. Data refer to Day 29 (end) of Expt. 1.

LSD $=$ least significant difference; $\mathrm{NA}=$ not applicable. significantly and on average almost halved the number of buds, flowers, and dry weight compared with a single plant (Table 1). In contrast, placing a Petunia with an Impatiens specimen rather than another Petunia resulted in proportionally taller plants, higher dry weight, and numbers of buds and flowers (Table 1), suggesting Petunia was very effective at competing for resources against Impatiens.

Data for flower number per unit dry weight (Table 2) indicated that reducing water availability enhanced efficiency of flower production $(P=0.001)$. Petunia plants that experienced both reduced water supply and competition within the container produced significantly more flowers/g dry weight (5.4) than well-watered, single specimens $(4.8$, LSD $=0.51$; Table 2). Despite significant reductions in attributes such as flower diameter (Table 1), a combination of compact plant stature and relatively high floral production efficiency in the " $25 \%$ ETp" treatments resulted in these plants retaining a good visual appearance.

Ornamental properties-Impatiens. The " $25 \%$ ETp" irrigation regime significantly reduced height, shoot number, dry weight, and flower number of Impatiens (Table 1). Placement with Petunia also largely reduced dry weight, shoot and flower numbers, although differences were not always significant. For example, flower numbers were significantly reduced in the " $25 \%$ ETp PI" treatment but not in the " $100 \%$ ETp PI" treatment (in which plants produced on average 26.7 flowers) despite presumably increased competition for water and light compared with a plant grown on its own (Table 1). Competition with Petunia seemed to influence biomass production, particularly when shoot dry weight per liter of water applied was reduced by placement with Petunia (Table 2). However, flowering based on the proportion of water directed to an individual plant was steady (nine to 10 flowers/L) with the exception of the drier regime for a single Impatiens specimen (" $25 \%$ ETp I"), which enhanced this ratio $(15.4$ flowers/L, LSD $=4.63)$. This treatment ("25\% ETp I") also gave a significantly higher efficiency of flower production (flowers/g dry weight) compared with the equivalent " $100 \%$ ETp" treatment (Table 2).

\section{Expt. 2}

Substrate moisture content was significantly different between " $100 \%$ " and " $25 \%$ ETp" treatments from Day 8, when they were $0.40 \mathrm{~m}^{3} \cdot \mathrm{m}^{-3}$ and $0.25 \mathrm{~m}^{3} \cdot \mathrm{m}^{-3}$, respectively (Fig. 3). From Day 11 until the end of the experiment, it was maintained at $\approx 0.4 \mathrm{~m}^{3} \cdot \mathrm{m}^{-3}$ and $0.15 \mathrm{~m}^{3} \cdot \mathrm{m}^{-3}$ for " $100 \%$ " and " $25 \%$ ETp" treatments, respectively. Differences in $g_{s}$ were measurable from Day 11 (Fig. 4). Maximum (daytime) air temperatures during the course of the experiment averaged $29^{\circ} \mathrm{C}$; mean daily sunshine duration was $4 \mathrm{~h}$ (data not shown).

There were considerably fewer flower buds in " $25 \%$ ETp" plants from Day 25 and 
Table 2. Shoot and flower production efficiency based on total and proportional volumes of water applied and flower number per unit of dry shoot weight for Petunia and Impatiens. ${ }^{2}$

\begin{tabular}{lccccc}
\hline & $\begin{array}{c}\text { Dry wt/vol. of } \\
\text { water (total) }\end{array}$ & $\begin{array}{c}\text { Dry wt/vol. of } \\
\text { water (per plant) }\end{array}$ & $\begin{array}{c}\text { Flower no./vol. } \\
\text { water (total) }\end{array}$ & $\begin{array}{c}\text { Flower no./vol. } \\
\text { of water (per plant) }\end{array}$ & $\begin{array}{c}\text { Flower no./ } \\
\text { dry wt }\end{array}$ \\
\hline Petunia & & & & & \\
100P & 3.0 & 3.0 & 14.1 & 14.1 & 4.8 \\
100PP & 1.4 & 2.9 & 6.7 & 13.4 & 4.8 \\
100PI & 2.0 & 3.9 & 9.4 & 18.9 & 4.7 \\
25P & 3.6 & 3.6 & 18.0 & 18.0 & 4.9 \\
25PP & 1.9 & 3.8 & 10.1 & 20.2 & 5.4 \\
25PI & 2.7 & 5.4 & 14.7 & 29.4 & 5.4 \\
LSD & 0.26 & 0.47 & 1.35 & 2.16 & 0.51 \\
df $=36$ & & & & & \\
Impatiens & & 2.1 & 9.9 & 9.9 & 4.8 \\
100I & 2.1 & 1.5 & 5.0 & 10.0 & 6.9 \\
100PI & 0.7 & 2.0 & 15.4 & 15.4 & 7.6 \\
25I & 2.0 & 1.4 & 4.6 & 9.2 & 6.4 \\
25PI & 0.7 & 0.40 & 3.58 & 4.63 & 2.28 \\
LSD & 0.25 & & & & \\
df = 24 & & & & & \\
\hline
\end{tabular}

"Plants were exposed to different watering regimes (" $100 \%$ " or " $25 \%$ ETp") and combinations of plants in the container $(\mathrm{P}=$ one Petunia $; \mathrm{PP}=$ two Petunia $; \mathrm{PI}=$ Petunia + Impatiens, and I = one Impatiens $)$. Data refer to Day 29 (end) of Expt. 1.

${ }^{\mathrm{y}} \mathrm{Based}$ on a 50:50 distribution of water to plants when two specimens were in a container. $\mathrm{LSD}=$ least significant difference.

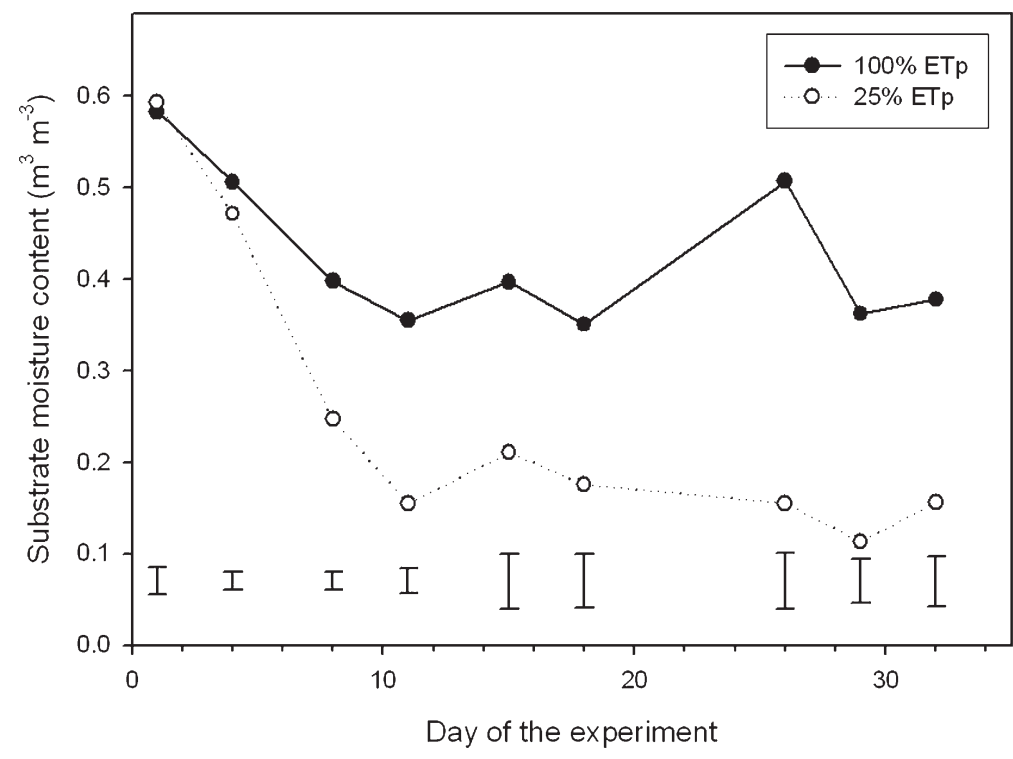

Fig. 3. Mean substrate moisture content per treatment over the course of Expt. 2. Vertical lines represent least significant difference $(\mathrm{df}=31)$.

this was reflected in fewer flowers in this treatment from Day 29 (Fig. 5). For any of the buds tagged during the experiment, there was no difference between " $100 \%$ " and " $25 \%$ ETp" treatments in the proportion of buds that developed into flowers (Fig. 6).

Difference in plant height was measured from Day 23 (e.g., $28.2 \mathrm{~cm}$ versus $23.7 \mathrm{~cm}$ for " $100 \%$ " and " $25 \%$ ETp" plants, respectively), whereas there was no difference in shoot numbers between " $100 \%$ " and " $25 \%$ ETp" treatments for the duration of the experiment (data not shown). Shoot dry weight at the end of experiment was on average higher for " $100 \%$ ETp" plants $(14.8 \mathrm{~g})$ than for " $25 \%$ ETp" plants $(10.2$ g) $(\mathrm{LSD}=1.20, P<0.001)$.

\section{Discussion}

Expt. 1 showed that the two species differed in their evapotranspiration under the optimal watering regime; the total watering volumes given to the Petunia were higher than in Impatiens (Fig. 1). This was not unexpected because Petunia is a more vigorous species, taller, and with greater shoot biomass and leaf area than Impatiens (Adams et al., 2008), thus apparently enabling it to transpire more under optimal conditions. However, adding a further plant increased watering requirements of such a container by only $5 \%$ and $10 \%$ (for PI or PP combinations, respectively) (Fig. 1). This is presumably a result of the total biomass (and hence evapo- transpiration demand) of two plants within the container being similar to that of a solitary plant in the same container.

In the " $25 \%$ ETp" treatment, the SMC was brought down to $\approx 0.10 \mathrm{~m}^{3} \cdot \mathrm{m}^{-3}$ from Day 12 in Expt. 1 and $\approx 0.15 \mathrm{~m}^{3} \cdot \mathrm{m}^{-3}$ from Day 9 in Expt. 2. For Petunia, at least, it has been suggested that droughted substrate covers a wide range between 0.22 and $0.09 \mathrm{~m}^{3} \cdot \mathrm{m}^{-3}$ (Nemali and van Iersel, 2006; Niu et al., 2006) and $g_{s}$ data from our experiment support this.

A decrease in SMC to $\approx 0.10 \mathrm{~m}^{3} \cdot \mathrm{m}^{-3}$ in Expt. 1 was linked to a significant reduction in plant size and flower numbers in both species. A reduction in plant size is a common response to reduced SMC (Cameron et al., 2006; van Iersel and Nemali, 2004). Reduced plant size can correlate closely with a decrease in flower numbers under reduced SMC (Guilioni et al., 2003), but flower number reduction can also be the result of decreased flower initiation and/or flower abortion (Cawoy et al., 2006; Turner, 1993). The data in Expt. 1 suggest, however, that plants in the reduced watering regime were more efficient at producing both biomass and flowers in relation to the volume of water applied (Table 2). Also, we found that Petunia plants that experienced both competition from other plants in the container and reduced watering regime had an enhanced efficiency of flower production (i.e., more flowers per unit biomass). In Impatiens, reduced watering did not improve efficiency of biomass production, but did improve flower production when there was no competition from Petunia (Table 2). To our knowledge, other studies into the watering requirements of ornamental plants did not set out to investigate these types of relationships per se. Nevertheless, interpreting data on Lupinus harvardii from Niu et al. (2007) suggests that flower production per unit biomass was reduced at the highest SMC $(0.3$ $\mathrm{m}^{3} \cdot \mathrm{m}^{-3}$ ) compared with lower SMCs, whereas the other treatments with SMC ranging from 0.12 to $0.25 \mathrm{~m}^{3} \cdot \mathrm{m}^{-3}$ did not differ in their flowering-to-weight ratios. Inferences can also be made from work on water use efficiency in edible crops. For example, recalculating data in pea plants subjected to low SMC $\left(\approx 0.20 \mathrm{~m}^{3} \cdot \mathrm{m}^{-3}\right)$ showed that flower numbers per unit shoot biomass increased in semileafless (but not in leafy) plants, possibly as a result of less competition between buds/flowers and vegetative growth for the available water (Baigorri et al., 1999). In food crops, however, most studies on water use efficiency focus, understandably, on yields rather than flowering (Passioura, 2004). Ecological studies highlight costs to plants associated with reduced water supply (e.g., a decrease of corolla size; Galen et al., 1999), but rarely interpret data in terms of efficiency of flowering.

Combination of Impatiens with Petunia largely decreased shoot and biomass production (but not necessarily flower production, e.g., at " $100 \%$ ETp") in the Impatiens. Indeed, poorest performance in Impatiens was associated with reduced irrigation supply 


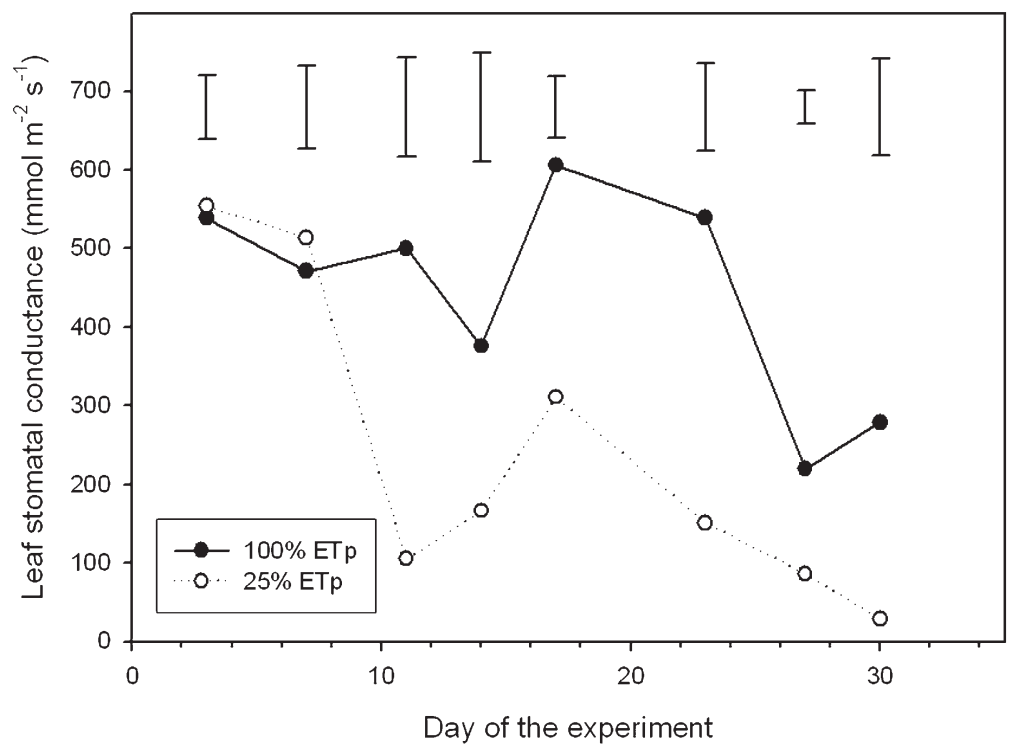

Fig. 4. Mean leaf stomatal conductance in plants subjected to " $100 \% \mathrm{ETp}$ " and " $25 \% \mathrm{ETp}$ " watering regimes in Expt. 2. Three leaves per plant on all eight plants per treatment were measured. Vertical lines represent least significant difference $(\mathrm{df}=46)$.

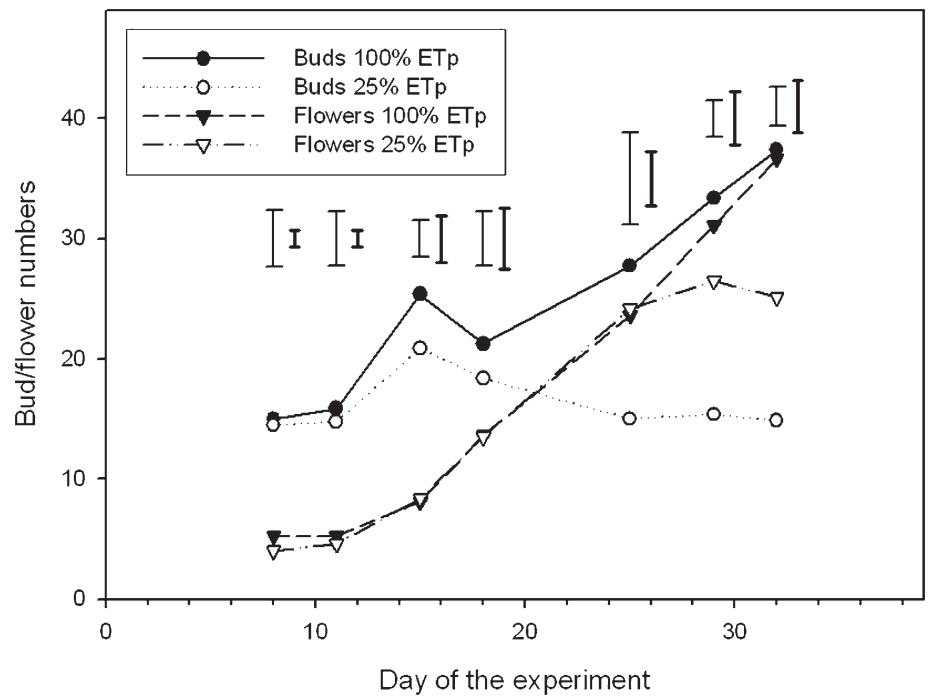

Fig. 5. Mean flower bud and flower numbers in plants subjected to " $100 \%$ ETp" and " $25 \%$ ETp" watering regimes in Expt. 2. Vertical lines represent least significant difference (LSD) $(\mathrm{df}=15)$; the thin and thick LSD lines enable the comparison within buds and flowers, respectively.

combined with competition from Petunia. Unfortunately, a treatment that incorporated two Impatiens within a container, as a comparison, was not included within the experimental design as a result of space restrictions and the fact that our primary interest lay with Petunia. In contrast to Impatiens, Petunia plants grew comparatively well when paired with an Impatiens plant rather than another Petunia (height, dry weight, flower and bud number often being significantly higher in the former combination). This may suggest that Petunia was the more effective competitor for water (and possibly other resources) under the conditions we imposed. It had been suggested that intra-/interspecific competition between multiple plants for belowground resources (water and nutrients), rather than the aboveground (light), is in most cases the main determinant of the loss of plant's quality (Weaver et al., 1994).

Although the reduced watering regime applied in Expt. 1 decreased flower numbers by $\approx 55 \%$ in Petunia, bud numbers were only reduced by $\approx 25 \%$ (Table 1 ). This may suggest that the reduced watering encouraged flower bud abortion. To clarify whether a proportion of buds abort under reduced SMC, we tagged visible floral buds in Petunia during Expt. 2 to monitor what proportion of those fully developed into flowers. For up to 14 $\mathrm{d}$ after differences in SMC were measured, the bud-to-flower conversion ratio was similar between the treatments. However, although statistically insignificant, a small decline in bud-to-flower conversion rate at the end of a monthlong experiment might suggest that after a prolonged period of exposure to low SMC, some flowers may be aborted.

There were some variations in plant responses between the two experiments. Flower numbers in " $25 \%$ ETp" Petunia plants in Expt. 2 were reduced by $\approx 25 \%$ as opposed to $\approx 55 \%$ in Expt. 1 . There was also a smaller reduction of shoot size and no reduction in shoot number between " $25 \%$ ETp" and " $100 \%$ ETp" plants in Expt. 2 compared with Expt. 1. This may be the result of the SMC being slightly higher in Expt. 2 (0.15 versus $0.10 \mathrm{~m}^{3} \cdot \mathrm{m}^{-3}$ ), confirming that Petunia has to be under severe stress for significant impacts on vegetative growth to be measurable (Henson et al., 2006). Weather conditions varied considerably between the two experimental periods, e.g., mean daily temperatures and net radiation were lower during Expt. 2, and this may have influenced the speed of stress imposition and the degree of stress experienced between irrigation intervals. Difference in temperature and irradiance would have influenced flower initiation too (Adams et al., 2001), because flower/g biomass was reduced in all plants in Expt. 2 (overall mean $=2.6$ ) compared with Expt. 1 (overall mean $=5.0$ )

Changes in climate and increased demand for water resources (Arnell, 1998) are likely to result in increased pressure (and possibly legislation in future) to reduce water use in ornamental horticulture, especially by local government and domestic homeowners. Rather than eliminating bedding plant displays outright, however, the data presented here indicate that acceptable bedding displays can be achieved even when water consumption is reduced by $67 \%$ below optimum. In reality, considerably larger savings are likely, because it is estimated that many containers are overwatered (Cotter and Chavez, 1979). Despite there being significant reductions in key ornamental plant parameters, these were not proportional to the reduced irrigation, i.e., in Petunia, reductions for flower number, height, and flower size were $55 \%, 33 \%$, and $13 \%$, respectively. Indeed, visually, there was often little loss of ornamental properties in Petunia under the lower irrigation regime; the plants appeared compact and retained relatively good flower cover in proportion to their biomass. For Impatiens, however, the growing of single plants at " $25 \%$ ETp" would be plausible, but the addition of a Petunia plant at " $25 \%$ ETp" was detrimental to plant quality (i.e., flower numbers reduced by $75 \%$ compared with a well-watered single specimen). Therefore, for Impatiens to have acceptable quality in a mixed container with Petunia, near-optimal irrigation is required.

Further research is required to investigate interspecific relations in a wider number of bedding species when water availability is reduced. Information in this respect, combined with the implementation of more sophisticated irrigation application and controlling equipment, may enable bedding plants to remain a feature of the urban landscape despite restrictions to water supplies in future. 


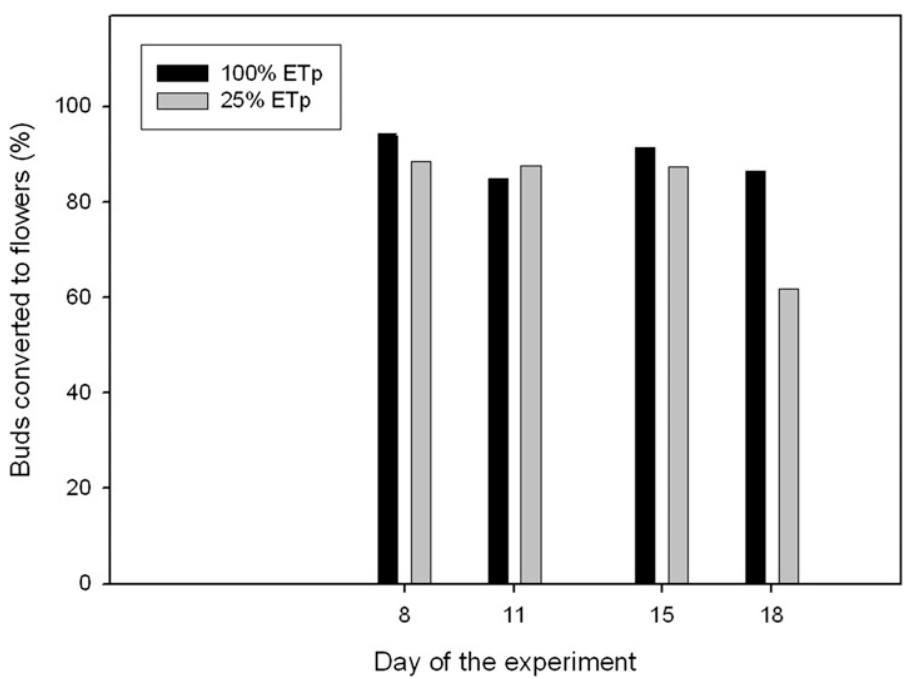

Fig. 6. Mean percentage of flower buds that developed into full flowers. Emergent flower buds on all plants were tagged on Days 8,11,15, and 18 of Expt. 2 and monitored for flower appearance for $10 \mathrm{~d}$ on each occasion. There were no significant differences between the two treatments on any date $(P$ values of $0.42,0.33,0.36$, and 0.27 for Days $8,11,15$, and 18 , respectively).

\section{Literature Cited}

Adams, S.R., S. Pearson, and P. Hadley. 2001. Improving quantitative flowering models through a better understanding of the phases of photoperiod sensitivity. J. Expt. Bot. 52: $655-662$.

Adams, S.R., V.M. Valdes, and F.A. Langton. 2008. Why does low intensity, long-day lighting promote growth in Petunia, Impatiens and tomato? J. Hort. Sci. Biotechnol. 83:609615.

Armitage, A.M. and T. Kowalski. 1983. Effect of irrigation frequency during greenhouse production on the postproduction quality of Petunia hybrida Vilm. J. Amer. Soc. Hort. Sci. 108:118-121.

Arnell, N.W. 1998. Climate change and water resources in Britain. Clim. Change 39:83-110.

Baigorri, H., M.C. Antolin, and M. Sanchez-Diaz. 1999. Reproductive response of two morphologically different pea cultivars to drought. Eur. J. Agron. 10:119-128.

Callaway, R.M. 2002. The detection of neighbors by plants. Trends Ecol. Evol. 17:104-105.

Cameron, R.W.F., R.S. Harrison-Murray, C.J. Atkinson, and H.L. Judd. 2006. Regulated deficit irrigation - a means to control growth in woody ornamentals. J. Hort. Sci. Biotechnol. 81:435-443.

Cameron, R.W.F., R.S. Harrison-Murray, and M.A. Scott. 1999. The use of controlled water stress to manipulate growth of container-grown Rhododendron cv. Hoppy. J. Hort. Sci. Biotech. 74:161-169.

Cawoy, V., S. Lutts, and J.M. Kinet. 2006. Osmotic stress at seedling stage impairs reproductive development in buckwheat (Fagopyrum esculentum). Physiol. Plant. 128:689-700.

Clark, D.G., C. Dervinis, J.E. Barret, H. Klee, and M. Jones. 2004. Drought-induced leaf senescence and horticultural performance of transgenic P-SAG12-IPT petunias. J. Amer. Soc. Hort. Sci. 129:93-99.

Cotter, D.J. and F. Chavez. 1979. Factors affecting water application rates on urban landscapes. J. Amer. Soc. Hort. Sci. 104:189-191.

Franco, J.A., J.J. Martinez-Sanchez, J.A. Fernandez, and S. Banon. 2006. Selection and nursery production of ornamental plants for landscaping and xerogardening in semi-arid environments. J. Hort. Sci. Biotechnol. 81:3-17.

Froud-Williams, R.J. 2002. Weed competition, p. 16-38. In: Naylor, R.E.L. (ed.). Weed management handbook. Blackwell Science, Oxford, UK.

Galen, C., R.A. Sherry, and A.B. Carroll. 1999. Are flowers physiological sinks or faucets? Costs and correlates of water use by flowers of Polemonium viscousum? Oecologia 118:461470.

Guilioni, L., J. Wery, and J. Lecoeur. 2003. High temperature and water deficit may reduce seed number in field pea purely by decreasing plant growth rate. Funct. Plant Biol. 30:11511164.

Henson, D.Y., S.E. Newman, and D.E. Hartley 2006. Performance of selected herbaceous annual ornamentals grown at decreasing levels of irrigation. HortScience 41:1481-1486.

Hunt, L. 2006. Water in the garden. The Royal Horticultural Society, Wisley, UK.

Murphy, G.P. and S.A. Dudley. 2007. Above- and below-ground competition cues elicit independent responses. J. Ecol. 95:261-272.

Nemali, K.S. and M.W. van Iersel. 2006. An automated system for controlling drought stress and irrigation in potted plants. Sci. Hort. 110:292-297.

Nemali, K.S. and M.W. van Iersel. 2008. Physiological responses to different substrate water contents: Screening for high water-use efficiency in bedding plants. J. Amer. Soc. Hort Sci. 133:333-340.

Niu, G., D.S. Rodriguez, L. Rodriguez, and W Mackay. 2007. Effect of water stress on growth and flower yield of big bend bluebonnet. HortTechnology 17:557-560.

Niu, G.H., D.S. Rodriguez, and Y.-T. Wang. 2006 Impact of drought and temperature on growth and leaf gas exchange of six bedding plant species under greenhouse conditions. HortScience 41:1408-1411.

Passioura, J.B. 2004. Water use efficiency in farmers' fields, p. 302-321. In: Bacon, M.A. (ed.). Water use efficiency in plant biology. Blackwell Publishing Ltd., Oxford, UK.

Philips, R. and M. Rix. 2002. Annuals and biennials. Pan Macmillan Ltd., London, UK.

Ray, J., S.E. Newman, and D.E. Hartley. 2003. Preplant plug growth regulator applications mediate inter-specific competition in mixed hanging baskets. HortScience 38:713.

Scheiber, S.M. and R.C. Beeson. 2006. Petunia growth and maintenance in the landscape as influenced by alternative irrigation strategies. HortScience 41:235-238.

Sims, C. 2006. Garden watering restrictions: A review of the hosepipe ban legislation. Department of Environment Food and Rural Affairs, Waterwise, UK. pp. 1-42.

Turner, L.B. 1993. The effect of water-stress on floral characters, pollination and seed set in white clover (Trifolium-repens L). J. Expt. Bot. 44:1155-1160.

van Iersel, M. and K.S. Nemali. 2004. Drought stress can produce small but not compact marigolds. HortScience 39:1298-1301.

Weaver, S.E., M.J. Kropff, and R. Cousens. 1994. A simulation model of competition between winter wheat and Avena fatua for light. Ann. Appl. Biol. 124:315-331. 